\title{
Canadian Emergency Nurses Caring During the COVID-19 Pandemic
}

April 7th, 2020

Dear Readers and NENA Membership,

This edition of the Canadian Journal of Emergency Nursing (CJEN) is being sent to publication while the COVID-19 pandemic is ramping up in Canada. Emergency nurses across the country are preparing for and facing this great emergency. During this year, designated the 'year of the nurse and the midwife' by the World Health Organization, we are being challenged in ways that few of us have imagined. We are practicing social distancing in our personal and professional lives. Our kids are home, schools and daycares have been closed across Canada. Millions of Canadians are without work following massive country-wide layoffs, there are supply shortages in hospitals and grocery stores, and nurses are going to work and grappling with the real risk of bringing home a potentially fatal infection.

Still early in Canada's pandemic response, multiple emergency nurses are already off sick and in isolation with COVID-19 infections. The stark reality is that Canadian emergency nurses may die as a result of the COVID-19 virus. Over one hundred health care workers have died already in Iran, Italy and Spain, Although not often talked about, this sobering thought underlies the actions we take. Nursing colleges and associations across the country are rapidly granting emergency practice licenses while at the same time suspending and finding alternative clinical experience for students. Hundreds of nonemergency nurses are being reassigned to existing emergency departments that are being expanded or temporary hospitals that are being established.

The sobering numbers coming from the countries hit by the pandemic before Canada suggest that we may be called to depart from dogmatic procedures and deviate from traditional practice. We may need to depart from restrictive infection prevention and control guidelines. Nurse leaders may, whenever possible, avoid assigning older nurses and those with high-risk comorbidities to highest risk aerosolgenerating procedures, and there is a possibility of the burden of caring becoming so great that typical functions like discharge teaching or documentation are approached differently. We believe that the Canadian Nurses Association, National Emergency Nurses Association, Canadian Federation of Nursing Unions, and provincial and territorial colleges recognize that this is an unprecedented time and trust you to act professionally and in the best interests of those you care for and yourselves.

Over the coming months, nurses and health care systems around the world will face the greatest peacetime challenge of the last century. As the language of care adopts the "martial" tone that underlies the stark realities we'll be facing we encourage you, our colleagues, to not lose sight of the "homefront" while we provide care in the "frontlines". Please remember that we're not just emergency nurses; we're mothers, fathers, sisters and brothers. We're all being thrust into the limelight, we'll be providing care in hospitals, support to our families, and a source of reassurance to our communities. The importance of our work will be recognized by the sacrifices we make to care for patients, in the support we give to our communities, and how we support each other as a profession. Canadian emergency nurses represent an integral part of our national pandemic response. During this response providing the 
best care may look very different than providing usual care; it's hard for us to anticipate what these changes look like; but we have faith that as a profession we will find the right path. None of us know what emergency nursing, or regular life, will look like at the end of this pandemic. We do know this: the most important step will always be protecting ourselves; without doing that we won't be able to care for our patients, our colleagues, or our families.

So as we put our affairs in order and prepare to do what we do best, take the time to tell your loved ones what they mean to you, be kind to your colleagues and neighbours and take the very best care that you can to protect yourself and your family.

All eyes will be on us. Emergency nurses are among the most important providers during this pandemic.

CJEN Editorial Leadership

Matthew J Douma

Christopher Picard

Heather McLellan

\section{Resources:}

To help us all prepare to work at our best, here are some internet educational resources that are free of charge:

Emergency Nurses Association - COVID-19 Resources

- This includes national and consensus guidelines, FAQ for ER nurses, a recorded webinar and 2 podcasts focused on patient care and avoiding burnout and some infographics.

- $\quad$ https://www.ena.org/practice-resources/COVID-19

American Association of Critical Care Nurses - Limited time free access to CE

- Multiple topics focused on critical care nursing practice

- https://www.aacn.org/education/ce-activities

Society of Critical Care Medicine - Critical Care for the Non-ICU Clinician

- Focused on physician practice but one module specific to nursing and a number of airway and ventilator topics.

- https://covid19.sccm.org/nonicu.htm

FEPA - Focused Education Preparation Advancing Frontline RNs

- Five online modules to help prepare the non-ER or ICU nurse for an increased level of practice 
- https://opencoursesstore.d2I.com/product?catalog=ftern 19xLOxU\&fbclid=|wAR1ILQgpE9Bhh1 -sMnWJUCQYNHEKynMOJ8RszRmZUnEUOUNEJHcLannDNRE

CFNU - Canadian Federation of Nurses Unions. Position Statement on COVID-19.

- https://nursesunions.ca/position-statement-on-covid-19/ 